\title{
Ways to Improve Emergency Ability of College Counselors
}

\author{
Jie $\operatorname{Liu}^{1, a,{ }^{*}}$ \\ ${ }^{1}$ Faculty of Mechanical and Electrical Engineering, Kunming University, Yunnan Kunming 650214, \\ China \\ a1459283539@qq.com* \\ ${ }^{*}$ Corresponding author
}

Keywords: College counselor, emergency response, capability.

\begin{abstract}
Under the new situation of social and economic development, college emergencies put forward new requirements for the counselor's emergency management ability. Based on the analysis of the problems existing in the emergency management, this paper puts forward the corresponding emergency management ability of college counselors. Countermeasures and recommendations.
\end{abstract}

\section{Introduction}

At present, colleges and universities have attached great importance to emergencies, adopted measures such as setting up emergency work leading groups, increasing the construction of counselors, and accumulated rich experience in the process of disposal, effectively improving the emergency management of counselors. Ability, but in the actual response work, the counselor personally has some weak links.

\section{Problems in the emergency management of college counselors.}

As the first-line educator of the struggle, the counselor is often the first aware of the information of the emergency, and the first one at the time of the treatment. How the role of the counselor directly affects the treatment effect during the whole process of the emergency, but because Institutional mechanisms and counselors' own reasons, in the emergency management of emergencies, often reveal some problems of the counselor personal.

\subsection{Counselor's work initiative needs to be improved}

At present, the work system of college counselors is still not perfect, the duties of counselors are unclear, the scope and content of the work are magnified, and the counselors are tired of coping with cumbersome transactional work, resulting in burnout and lack of initiative. The counselor's income, evaluation mechanism, and professional title evaluation system are not perfect, so that the counselor can not experience the sense of professional belonging, and it is difficult to make them feel comfortable in the counseling position. As analyzed above, these factors will inevitably weaken the counselor's work initiative and enthusiasm. They will not be able to position themselves well in the role and role of emergencies, and have insufficient understanding of the dangers of emergencies and poor handling. Just passively tired of coping.

\subsection{Counselor emergency management knowledge reserve and skills}

When recruiting counselors, colleges and universities not only pay attention to academic qualifications, but sometimes they are interested in hiring students with professional expertise, which causes counselors to be uneven in the background of education management, professional quality is not strong, and because they are busy with numerous transactional work, counseling It is difficult for employees to give special energy to study and study emergency management knowledge and skills; In addition, the colleges and universities have targeted training on public events, natural disasters, 
psychological interventions, firefighting, etc., which will inevitably lead to the shortage of counselor's emergency management knowledge reserves and skills.

\subsection{Counselors are less sensitive to emergencies and have a weaker sense of crisis}

Due to the lack of professional initiative and responsibility, and the lack of professional knowledge and skill reserves, it is inevitable that it will reduce the sensitivity and crisis awareness of emergencies, and will not be able to predict the upcoming crisis well. The danger of the event; The role of self-discipline in the process of emergency handling is not allowed, sometimes there is shirking responsibility, the crisis that should be avoided is broken out as usual, and the conflict that should be effectively controlled cannot be effectively curbed, bringing no problems to students and schools. Necessary damage and loss.

\section{Emergency response improvement approach}

\subsection{Improvement of prevention ability}

"Everything is pre-established, not pre-emptive." The emergency management of counselors should adhere to the principle of prevention and safety first, and timely and properly handle unexpected incidents among students. This requires counselors to establish a sense of crisis in their daily work, continuously improve their overall quality, smooth information channels, familiarize themselves with policies and regulations, and conduct systematic analysis and judgment, thereby strengthening early warning and effectively preventing emergencies and maintaining campus security and stability.

\subsubsection{Have a strong self-quality}

"Blacksmith need its own hardware". "Strong politics, hard work, strict discipline, and fine business" are the overall requirements for the team of college counselors. To do a good job in emergency management, the counselors must have a high quality. First of all, college counselors must have a sense of emergency warning, and be safe in times of peace, in order to build a stable and stable campus. It is necessary to fully recognize the importance of emergency warnings for emergencies and firmly establish awareness of emergency warning. Secondly, we must have a high sense of responsibility and a strong sense of professionalism; always be student-centered, have a correct working attitude and good work habits; at the same time, we must have keen insight, high alertness, and be able to detect students in time. Bad information points. Again, be a thoughtful person. Unexpected incidents often occur in an instant, and they are fierce. They are not allowed to inspect the survey for a long time, understand the reasons, and discuss countermeasures. Therefore, the counselor should pay attention to the accumulation of information and experience in the usual work, keep the sensitivity and vigilance of the work at all times, and achieve early detection, early alertness, early judgment, early treatment, and killing adverse events at the head. To prevent conflicts from escalating and escalating events. Finally, we should strengthen the care, care and guidance of the students' mind and body, and link the daily management, psychological counseling, funding, employment and emergency warning work, so that the alarm bells can be heard to effectively prevent emergencies.

\subsubsection{Have a competent team of informants}

"Knowing ourselves and knowing each other, there is no war." Counselors must do a good job in emergency management, and it is necessary to build a strong team of informants.

\subsubsection{Have skilled policies and regulation}

The handling of emergencies needs to follow the relevant rules and regulations. Therefore, the counselors should be familiar with the spirit of the documents and specific rules and regulations governing student management issued by the state, provinces, cities, schools, etc. Only in this way can we be confident and confident. Address the specific issues in the handling of incidents. 


\subsection{Improvement in execution ability}

The occurrence of unexpected events in colleges and universities is uncertain and rapid. As a counselor who is in the front line of student work, it cannot be avoided. Only calm and rational, objective analysis, can calmly cope, avoid arbitrarily qualitative, recklessly act; Neither tweeting nor falsifying, we must be sincere, sincere and positive to face the incident and the parties, relying on the strength of the team and the collective to do a good job in the handling of the incident. In the emergency management, how the executive ability of the current front counselor is undoubtedly the ability to properly handle the incident is improved. The ability of the counselor in the emergency management can be improved through the following three aspects of ability development.

\subsubsection{Rapid response ability at the time of the incident}

The speed of response depends on whether the counselor has crisis awareness and certain sensitivity in his daily work, and whether he can detect the clues of the incident in a timely manner. The rapid response capability requires the counselor to arrive at the scene at the first time of the incident, use all available resources to control the situation, guide the crowd, stabilize the mood, adhere to the student-centered, act decisively, make judgments, and prevent the situation. Further spread and worsen. At the same time, as far as possible to find out the reasons, the passage, development and possible consequences of the matter, to find the root cause of the problem, to achieve targeted. According to the actual situation of the incident, organize on-site rescue to minimize losses. "When the situation calms down, the counselor will clear the incident, get the first-hand information, and save the on-site evidence. At the same time, the cause and effect of the incident, the situation on the spot, the progress of the incident, the development of the situation and the trend of prediction will be timely. Report to the superiors, listen carefully to the opinions, and implement them one by one." When necessary, it is necessary to communicate with the parents of the students in a timely manner to gain their understanding and support. After the situation has subsided, the specific process of understanding the incident will be investigated in detail, the relevant evidence will be found, and the written materials will be formed and reported. The rapid response ability requires the counselor to have the psychological quality of being in a hurry and calm, and the counselor is required to have a calm and objective analytical ability and the ability to handle it on the spot. These require counselors to pay attention to continuous exercise, accumulation and summary in their daily work.

\subsubsection{Effective communication skills}

Effective communication can often have a multiplier effect. In the process of handling emergencies, the counselor must have the ability to control information communication, not only to correctly guide the public opinion, but also to deal with the relationship between the parties and the parents of the students, to make a good communication bridge between the school and the parties, and also It is necessary to rely on the organization, learn to take care of the overall situation, communicate with each other, work together, and work together to handle the incident.

\subsubsection{Posttreatment ability}

In the emergency management work, the counselor follows up in the whole process of the occurrence, development and subsidence of the incident. The aftermath of incident handling involves the healthy development of students and adult achievement, as well as the harmony and stability of the campus Counselors should not only do the psychological comfort work of the relevant students, but also do a good job of calming and calming other students' emotions. After the event, we should conduct psychological counseling for individuals and groups in a timely manner to reduce the impact and harm of the incident. In order to eliminate the negative impact of emergencies and reverse the negative attitudes of students, counselors should try their best to guide public opinion and transfer the main energy and focus of students to study and life; On the other hand, it is necessary to organize active and healthy cultural and sports activities to create a good atmosphere. Since the aftermath involves the interests of the students, it is necessary to take care of the students' vital interests and meet their reasonable needs. At the same time, counselors must pay attention to the other students' ideological dynamics and follow the prevention-oriented approach to prevent similar incidents from happening again. Finally, counselors should summarize the disposal work, learn lessons, propose 
targeted and creative improvements, improve the early warning and disposal mechanism for emergencies, and accumulate rich practical experience for future emergency management.

\section{Conclusion}

The social attention of college emergencies is high, and the speed of communication is fast, which is likely to cause some bad social impacts. As the front-end team of student work, college counselors are the most direct and close contact with students, and they are an important force in dealing with emergencies. Therefore, in-depth study to improve the emergency management ability of college counselors is of great significance for maintaining campus security and stability, and ensuring social stability and harmony.

\section{References}

[1] W. C. Qian, Research on emergency management of college emergencies, Journal of Yunnan Administration College, No.4, pp 5-6, 2010.

[2] Z.P. Chen, The ability of college counselors to respond to campus emergencies, Journal of West Anhui University, No.6, pp 27, 2011.

[3] G. Feng, Counselor Work Training Course, Higher Education Press, pp 218, 2013. 